\title{
Resilience: A personal attribute, social process and key professional resource for the enhancement of the nursing role
}

\author{
Resilienza: attributo personale, processo sociale e risorsa professionale chiave per il \\ rafforzamento del ruolo dell'infermiere.
}

Margaret McAllister ${ }^{1}$

\begin{abstract}
Resilience is the positive adjustment to adversity. Nursing work is characterised by assisting patients and families to cope through varying types of adversity- accidents, illness, disasters and upheaval and also in encouraging and supporting people to adapt, recover and maintain wellbeing. Thus strategies to promote resilience need to be integral to nurses' daily practice. Adverse conditions are also commonly experienced by nurses themselves and this impacts negatively on attitude to work, stress and burnout and this affects the whole profession through ongoing shortages, and disengagement with the work still to be done by nursing in terms of research and practice development. This paper will discuss the meaning of resilience, how it has been researched and applied to health care and to nursing. It will suggest pro-active strategies that educators, researchers and clinical nurses can implement that work on building strength, focus and endurance in individuals, communities and the workplaces.
\end{abstract}

Key words: Stress, Adversity, Disasters, Nursing, Resilience

\section{RIASSUNTO}

La resilienza è il modo di affrontare positivamente le avversità. Il lavoro dell'infermiere è caratterizzato dall'assistere i pazienti e le famiglie nel far fronte a vari tipi di avversità quali ad esempio: incidenti, malattie, disastri come anche nell'incoraggiare e supportare le persone verso la guarigione ed al mantenimento del well being. Quindi le strategie per promuovere la resilienza devono essere parte integrante della pratica quotidiana dell'infermieristica.

Situazioni difficili sono anche comunemente vissute dagli infermieri stessi e questo ha un impatto negativo sul comportamento nel lavoro, comportando anche stress e burn out. Questo ha effetti negativi su tutta la professione in termini di scarsità di personale e distacco da quanto dovrebbe essere ancora fatto dall'infermieristica in termini di ricerca e pratica.

Questo articolo discuterà il concetto di resilienza come è stato studiato ed applicato all'health care ed all'infermieristica. L'articolo suggerirà strategie che insegnanti, ricercatori e infermieri clinici potranno implementare al fine di rafforzare il lavoro sugli individui, comunità e luoghi di lavoro.

Parole Chiave: Stress, Avversità, Disastri, infermieristica/Infermieri, Resilienza

\section{INTRODUCTION}

\section{WHY RESILIENCE IS IMPORTANT IN NURSING}

$\mathrm{M}$ ost people in developed countries are living longer, principally because of bio-technology and the availability of sophisticated treatments, but often this involves receiving ongoing health-care, managing one or more chronic disease, and coping with inadequate support systems (Gaynor et al 2006). Whilst people may have a longer life span, it is not clear whether all people would consider this an enjoyable life.

When ill people meet nurses, they are often in crisis, whether physically, psychologically or both. The treatment that is provided is complex and short-term, and frequently patients are discharged with health

\footnotetext{
1 RN, Ed D, FACMHN, FACN, Professor of Nursing, Central Queensland University, Goodchap Street Noosaville, 4566.

Corrispondence: Email: m.mcallister@cqu.edu.au
}

issues that are still resolving, but with limited confidence in self-management. It is likely that there will be a period of adaptation and struggle ahead for them. For nurses, just as one patient leaves, others come in to replace him or her and the work continues. The lack of 'down-time', and inevitability of further crises, can be very stressful for nurses and when this stress is perceived negatively or is overwhelming, it constitutes adversity (McAllister \& Lowe, 2011).

Scholars argue that this situation explains the high rates in nurses of substance abuse, non-communicable diseases such as coronary artery disease, diabetes, mental health problems, burnout and ultimately workforce shortages (Wieclaw, Agerbo, Mortensen et al., 2006). Investigating the conditions in which patients, nurses and others are able to bounce back from adversity, and in so doing demonstrate resilience, is therefore important for nursing to research. 


\section{WHAT IS KNOWN ABOUT RESILIENCE}

Put simply, resilience is a phenomenon of positive adjustment in the face of adversity (Masten \& Powell, 2003). International research on resilience has been occurring for well over 50 years, but in the last two decades in particular, there has been increased activity. Windle, Bennett and Noyes (2011) suggest that this is because of the growing dissatisfaction with 'deficit' models of illness. Deficit models of illness are those that focus on problems and deficiencies. Alternatives to these models come from the strengths and wellbeing framework where health practitioners are interested in exploring what attributes, processes and resources people have already and which can be harnessed and amplified to promote recovery and adaptation. Individual, environmental and community resilience is one of these important resources that people may have to promote their wellbeing. For nurses themselves, resilience may also help to achieve and maintain professional self-efficacy and longevity in the workforce.

Resilience researchers are interested in exploring how and why resilience helps some people or communities to be resistant to risk across the lifespan and why some people bounce back from adverse situations such as war, imprisonment, torture, repeated misfortune, or ongoing ill-health. Thus, resilience is an important factor or strength that may have an influence on health, wellbeing and quality of life.

Although the concept of resilience dates back to the 1800s, it was not until the 1970s that work on resilience in social and health contexts expanded (Luthar \& Cicchetti2000). A constellation of activities and insights stemming from ecology, health, public health and well publicised stories from survivors, culminated in a paradigm shift away from deficits and illness, towards strength and wellbeing (See Fig 1).

In the autobiographical book "Rise" (2008), Ingrid Poulson recounts the 2003 horrific tragedy, and her survival, from her ex-husband raping her and then brutally murdering her father and child. The book recounts not just the event, but Ingrid's recovery, which she attributes to the development of resilience strategies, which she coined "R.I.S.E" - Resolve, Identity, Support and Everyday. For her, resolve is about promising and giving yourself permission to survive and move forward; Identity is emphasizing the aspects of your character which have resilient qualities such as flexibility or empathy; Support is realizing that you need the support of other people whatever inner strength you may have; and Everyday is about eating healthy food, exercising and getting enough sleep.

Figure 1: Autobiographies stimulate the strengths focus.
Ecology researchers began to examine an ecosystem's capacity to absorb shocks and still maintain function (Folke, 2006). As concerns for sustainable environments increased, researchers began to identify and explore factors within a system that gave it capacity for renewal, reorganisation and development.

Interestingly, these studies have been paralleled in the health literature. At first there was interest in how people bounced back from adversity and managed to keep living relatively well. For example in the early 1980 s a series of studies were undertaken to explore the children of parents diagnosed with schizophrenia and why some of them seemed to survive this experience of adversity relatively well (Billings and Moos,1983; Kauffman et al, 1979; Garmezy, Masten \& Tellegen, 1984; Worland, Weeks \& Janes, 1987).

Subsequent studies of marginalised children and adolescents in adverse circumstances showed that, within communities, young people deal with and overcome adversity better and are able to envision a future for themselves when certain factors are present (Aronowitz, 2005). These protective factors include: social connection with family, peers and other adults; positive role modelling of winners or achievers; unobtrusive monitoring of wellbeing; and coaching to help in goal setting and elevating expectations. A converse set of factors put children at risk of stress breakdown (Feldman, Stiffman \& Jung, 1987).

In nursing, this theory has been supported through research findings, particularly in children. For example, Dowling, Hockenberry \& Gregory (2003) in their studies of children with cancer found that sense of humour, family support and continued social involvement are correlated with successful adaptation to treatment. On the other hand, depression and disinterest in physical activity is predictive of poorer quality of life in adolescents with cancer (Chung et al., 2002).

Resilience research has now extended to adults. For example, research with people with schizophrenia showed that those with less severe symptoms were more likely to have positive outcomes in areas of employment, responsibilities and social relations, including marriage (Luthar, Cicchetti \& Becker, 2000). These insights supported the justification of mental health interventions that targeted social and occupational factors, in addition to symptom management. The research also prompted thinking on factors to support wellbeing and productivity in other groups. A paradigm shift for health practitioners had begun.

Antonovsky's (1987) concept of Sense of Coherence, which is influential in the public health discipline, is an example. In this concept, a person's ability to cope in times of stress depends on three factors: (a) meaningfulness, the profound experience that this 
stressor makes sense in one's life and thus coping is desirable; (b) manageability, the recognition of the resources required to meet the demands of the situation and a willingness to search them out; and (c) comprehensibility, the perception of the world as being understandable, meaningful, orderly and consistent, rather than chaotic, random and unpredictable.

The paradigm shift also includes learning from stories of survivors of the holocaust, such as Viktor Frankl (1979) Primo Levi (1979) and Elie Wiesel (1959) all of whom not only survived the deprivation and misery of living in a concentration camp, but who came out of their ordeals changed men. All were moved to write books about their experience, interrogating the meaning of humanity. Frankl became a psychiatrist, who founded an approach known as logotherapy, an important contributor to humanistic psychology. Levi became a major literary figure in Italy and Wiesel, also a writer and scholar, has been the recipient of numerous humanitarian awards, including the Nobel Peace Prize.

Analysis of people and phenomena such as this, where adversity leads to growth, has taught us much about the personality and dispositional characteristics of resilient people (Linley \& Joseph, 2004, Tedeschi $\&$ Calhoun, 2004).

\section{THE CHARACTERISTICS OF RESILIENT INDIVIDUALS AND COMMUNITIES}

Resilient individuals seem to possess personal attributes that help them get through ordeals (DenzPenhey \& Murdoch, 2008). These attributes are listed, and where necessary explained, in Table 1.

Note that some of these attributes are internal and others exist in the external world. Thus resilience may involve ability to access inner and external resources to effectively deal with adversity (Friborg et al., 2003).

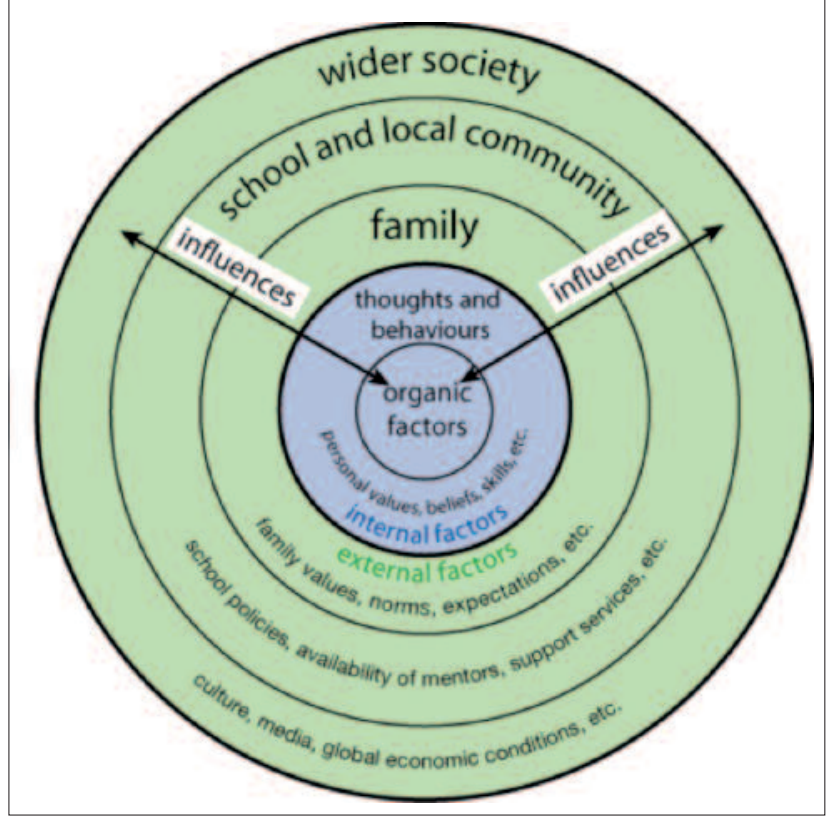

Figure 2. An ecological model of resilience

Whilst individuals can demonstrate resilience, so too can groups and cultures. The ecological model of resilience (Masten \& Powell, 2003) illustrates the possibility of there being a web of bi-directional relationships between individuals and groups such as family, school, peers, neighbourhood and the wider society (Figure 2).

This broader view of resilience has also recently been applied to the work context. Resilience frameworks to assist employees within organisations have been developed (Walsh, 2003) and campaigns aimed at the general public have been launched (Newman, 2003). Both aim to boost resilience in groups of people experiencing life stressors.

Furthermore, resilience may be viewed as a complex cultural construct that includes the concept of groups such as families demonstrating resilience, with dynamic interactions between individuals and group members promoting positive adaptation to

\begin{tabular}{|l|l|}
\hline Attribute & Explanation \\
\hline \multirow{2}{*}{ Internal locus of control } & $\begin{array}{l}\text { Refers to the extent to which individuals believe that they control events that affect } \\
\text { them. For example, when Jane fails an exam she says to herself "I take responsibility for } \\
\text { that. I should have studied harder". }\end{array}$ \\
\hline Staying calm & Circumvents the stress response, and enables problem-solving \\
\hline Sense of Humour & Brings in joy and positive emotion \\
\hline Optimism & Hopeful about the future \\
\hline Ability to transcend & Imagines the self somewhere more pleasant beyond the present reality; a spirituality \\
\hline Connectedness to the social/cultural/phy- & Finds solace in the camaraderie of others or in nature \\
\cline { 2 - 2 } sical environment & For example, an indigenous Australian finds comfort in being with/in the land \\
\hline Has a repertoire of coping mechanisms & $\begin{array}{l}\text { Productive coping mechanisms may include repression, displacement, minimisation, } \\
\text { sublimation }\end{array}$ \\
\hline Generativity & Helpful, involved in, and giving back to others \\
\hline
\end{tabular}

Table 1. Resilience attributes 
adverse experiences (Luthar, Cicchetti \& Becker, 2000). Similarly, examples of cultural and community resilience demonstrate that factors such as attachment to land, family, culture and community enable groups to deal with adversity, and in so doing reach a higher level of functioning (Clauss-Ehlers Levi, 2002, Lothe $\&$ Heggen, 2003). Participation in community activities also promotes the development of social networks and these networks also provide support to less resilient members of the community (Boykin et al., 2003).

Resilience may also be contextual and dynamic: individuals may not display resilience in all aspects of their lives, and different life transitions that require specific coping mechanisms, social supports or spiritual strength may activate different genetically determined biological reactions (Tusaie \& Dyer, 2004). In addition, some resilience resources may be readily available in some contexts but not in others. For example, social supports may be forthcoming in situations that involve publicly acknowledged crises, but when that crisis is associated with stigma or shame, then supports may not be accessible, and maintaining resilience may require coping of a different magnitude or quality (Deveson, 2003). Thus resilience involves an interaction between the stressor, context and personal characteristics.

\section{RESILIENCE CAN BE LEARNED}

There is convincing evidence that individuals can learn or acquire resilient qualities. Within the positive psychology movement, Seligman's (1998) work on learned optimism, for example, argued that a person's explanatory style shapes the meaning and the effect of adverse experiences. Moreover, one can learn to be optimistic by using focussed cognitive behavioural techniques that dispute pessimistic thinking and allow the individual to become more adaptive and resilient. Resilient Vietnam prisoners of war were found to share 10 personality traits, and a number of these traits can be developed with Cognitive Behaviour Therapy (Charney, 2004).

Within the educational context, evidence suggests that resilience can be improved through the provision of relevant and practical protective factors, such as an educational setting that is caring and learner-centred, has positive, high expectations and provides a positive learning environment, is placed within a strong, supportive, social community, and offers supportive peer relationships (Rapp, 1989, Gu \& Day, 2007). Conversely, educational experiences that provide only one way transmission of information, rather than transaction, may prepare students inadequately, giving them little know-how for workplace survival and rendering them vulnerable to future stress (BoixMansilla \& Gardner, 1999).

An alternative educational framework that focuses on interaction and know-how development is transformative education (Mezirow, 2000; McAllister, 2005). The concepts of transformative education have their foundations in critical social theory, a theory that explores and develops concepts and practices to promote social justice and equality. The topics of concern in the transformative learning environment are experiences of marginalization, injustice, power inequities and dilemmas. So the concept of adversity is fitting in this framework. At its heart, transformative education goes beyond the mere acquisition of cognitive, affective and psychomotor skills that may produce competent, but not necessarily critical, empowered and empowering knowledge workers. Instead, it seeks to use critical and constructive thinking methods to inspire learners to look deeply into practices, to develop creative ways of thinking, to improve problem solving and to strive to further social good through concerted personal actions. Thus the learning of resilience fits well with the transformative educational framework.

\section{RESILIENCE RESEARCH IN HEALTH PROFESSIONALS}

As resilience may be a personal, social and cultural strategy for surviving and even transcending adversity, it can be used as a concept for exploring and understanding health professionals who survive and thrive in this workplace. Research within health professional groups that experience high exposure to potentially traumatic experiences, such as emergency nurses and ambulance and paramedic personnel, has found that characteristics such as extroversion, openness, agreeableness, conscientiousness and coping levels influence posttraumatic growth (Shakespeare-Finch, Gow \& Smith, 2005). Some of the risk and protective factors that have been identified in groups such as soldiers, prisoners of war and displaced or traumatised people are directly applicable to health professionals. However, exploratory and intervention-based research using resilience to deal with stress in the health workplace is only in its infancy (Gillespie et al., 2007; Jackson, Firtko \& Edenborough, 2007) .

In their review of the literature, Jackson et al. (2007) view resilience as a quality necessary to succeed in nursing, because the conditions can be so adverse. They distilled five strategies to develop resilience in nurses: (1) building positive professional relationships through networks and mentoring; (2) maintaining 
positivity through laughter, optimism and positive emotions; (3) developing emotional insight to understand one's own risk and protective factors; for example, whilst caring is central to the work of nurses, many neglect self-care, an important aspect of resilience; (4) using life balance and spirituality to give one's life meaning and coherence; (5) becoming more reflective to help in finding emotional strength and assist in meaning-making in order to transcend the present ordeal. These authors argue for the need to teach and encourage health professionals to: identify their own risk and protective factors; share experiences of resilience and vulnerability so that others may learn from and perhaps emulate the strengths and avoid the pitfalls; acknowledge and praise success in peers' achievements; and promote feelings of pride. All these strategies help to build resilience and are directly transferable to other health professional groups.

Resilience research has explored, amongst other things such diverse issues as survivors of : the holocaust (Cassel \& Suedfeld, 2006), cancer (Rowland \& Baker, 2005), AIDS (Rabkin et al., 1993), and the September 11 attacks (Butler et al., 2005). In all of these studies, the common finding has been that many of these people not only survived an ordeal, but were somehow enlightened and their lives actually improved following the trauma.

\section{FUTURE RESEARCH}

Learning from the insights of individual health professionals and relating these insights to wellbeing is also important. In addition, the clinician's orientation to the nature of the work and how meaningful it is to his or her own life may be significant; if the work is 'just a job', as it is for some clinicians, then this viewpoint may be correlated with lower levels of resilience. Researching how clinicians process and understand experiences that are significant or even traumatic, such as the first time they face an untimely death of a client, could also yield valuable information; the coping styles and capabilities that clinicians bring to their work, either through genetic or environmental factors, may well help them endure challenges and even grow from them.

A concept within the public health discipline that is yet to be linked to workplace resilience in the health workforce is the settings approach to health promotion, with its emphasis on system change and the notion of building 'healthy hospitals' (Baum, 2008; Noblet, 2003). This concept applies health promotion principles not to individuals, but to the physical and built environments in which people work and live, with the assumption that supportive, preferred working environments for health workers have an increased capacity to improve overall health and wellbeing (Baum, 2008). How healthy work environments contribute to overall resilience is an area worthy of investigation, particularly in health workplaces that are becoming busier as the biotechnology boom increases client turnover, client longevity and use of health services.

To date, the prevailing research paradigm within the health sector remains problem-oriented (McAllister, 2007, Robinson \& Sirard, 2005) and focuses on reductionist approaches to understanding causative mechanisms of risk and protective factors for workers. Ideally, exploratory and interventionist research using resilience as a tool should employ an alternative paradigm that is strengths and solutionsoriented, in order to explore issues from a preventive and proactive point of view. Solutions-oriented research questions should be asked. For example: Does adding peer mentorship to the health workplace increase work satisfaction levels? Does creating relaxing surrounds in common rooms for health professionals enhance the quality of interaction between colleagues? The answers to such questions can enable educators, policy makers, managers and clinicians to identify, introduce and evaluate novel strategies to prevent stress, burnout and neglect, to create healthier, more harmonious workplace cultures and to recruit and retain high achievers in the health professions. As well as reducing attrition rates and skills shortages, such innovations are likely to increase client satisfaction and improve use of health services.

As the evidence suggests that resilient qualities can be developed through positive learning experiences, the knowledge gained from the research described above can then be incorporated into evidence-based educational programs for teaching resilience. Evaluating the effectiveness of such programs provides another important area of research.

\section{IMPLICATIONS FOR THE NURSING ROLE}

All of this information on resilience has implications for how nurses can encourage and support patients. Firstly, they should assess the strengths that exist in the person, their family and environment, and aim to utilise these so that they operate as support structures during the illness and adaptation experience. Educating people about the benefits of developing a wide repertoire of coping mechanisms may be very useful in raising awareness of resilience.

Explaining healthy coping mechanisms and together developing a relevant list can be helpful. Strategies might include: exercise, yoga, meditation, conversa- 
tion, reading, listening to music, looking at photographs, or using heat or cold applications. Encouraging patients by identifying realistic short term goals and then commenting positively on what is being achieved and the progress made can cultivate hope and optimism for the future.

There are also practices that nurses can engage in to contribute to a happier, healthier nursing work culture. Health environments can be notoriously bureaucratic and hierarchical, and vulnerable new nurses will likely experience ideological tensions, power inequities and ethical dilemmas. As newcomers, they may experience self-doubt and tentativeness, and lack connectedness in their workplace. More experienced nurses can facilitate a sense of belonging in the new staff by welcoming them, appreciating that timidness, aloofness and solitude may indicate lack of confidence and signal the need for friendliness, and encouraging reflection on practice so that puzzles and tensions can be worked out in an environment of collegial support, where gentle interruptions to guide best practice and minimise errors are possible (McAllister, Tower \& Walker, 2007).

New nurses benefit from exposure to positive role models who can share strategies on how to thrive in health workplaces. Imitative learning is a powerful learning strategy, which will benefit the new nurses. The experienced ones will also benefit because their sense of generativity will grow. Generativity, or altruism, is a resilience attribute and involves giving back to the new generation, continuing to make a positive contribution to the culture.

By enabling and valuing generativity in the workplace we also make better use of our nursing elders and help them to feel fulfilled which is an asset for the profession. There are many ways to enable generativity. For example, resilient clinicians could be encouraged to share lessons from their experiences for the benefit of the future workforce through dialogical activities such as shared storytelling at seminars and conferences and through publications and creative expression such as poetry, art, autobiographical writing and film.

Leaders and managers can develop a less bureaucratic decision making style so that people feel involved and therefore more loyal to the workplace. Some strategies to do this include:

1. Actively supporting time away from hands-on nursing so that thinking time is possible. This time could be used for positive role models to support reflection on practice. These sessions might focus on helping nurses to find meaning in challenging situations ( how did their role make a difference?), manageability (how can these situations be managed better next time?) and comprehension of experiences (why did this happen in the way it did?).

2. They can invite experienced nurses to act as mentors to new staff and develop a relationship where the new staff feel comfortable in interrupting practices if there is risk errors through omission or commission.

\section{IMPLICATIONS FOR NURSING EDUCATION AND SUPPORT}

Resilience is relevant to everyone's wellbeing and since nurses and nursing students may be particularly vulnerable because of the stress they experience, it ought to be a concept that is taught in engaging and memorable ways.

Developing a confident, proud identity can build self-belief and a calm demeanour under stress. Therefore discussions of positive role models in nursing, inclusion of nursing history so that students can see how far nursing has developed and what obstacles have been already overcome can develop a sense of social connectedness and belonging (See Table $\mathrm{x}$ ). Asking students what they believe in, what their aims are, what they intend to contribute to the world are all strategies to develop a sense of professional optimism and commitment.

It is also vital that students be responsibly prepared for the stressors and potential for adversity that is common within complex health systems. One way to do this is to include resilience into the curriculum and engage students in reflection for practice. That is, to prompt students to consider and to brainstorm the following:

1. What are my strengths that I could draw upon to help me during stressful times at work?

2. What are my coping skills that I have used effectively in the past to cope with stressful situations? Is there room for extending my repertoire?

3. What do I need to know about what it takes to succeed out there?

4. What am I likely to encounter in hospitals and health centres that I need to be prepared for? 5. How can I develop critical thinking, creative thinking and a sense of humour to help me cope? 6. What can I do when I am on clinical placement that may help to contribute to a happy, collaborative atmosphere amongst the team?

Another strategy to build a sense of professional belonging and thus resilience is to provide a forum where a range of students, nurses and community allies can come together to exchange ideas and celebrate the positive achievements of nursing. For six years, I have organised novel events to remember International Nurses' Day. Our team has organised guest speakers to discuss landmark moments in 
nursing's history and photography competitions to invite students to contribute positive images of nursing for the media (McAllister et al., 2011).

One important aim for educators is to build strengths that equip students with interpersonal and psychosocial strategies to help them make a successful transition to the heath workplace, to prepare them for the pressures and challenges of the work environment and to encourage their social activism to build more inclusive, supportive workplaces.

\section{RESILIENCE-BASED THINKING IN NURSING}

Nurses can powerfully reorient their practice to be strengths-based, simply by changing the way they speak to and about clients. For example, when conducting a health assessment, one could ask, "What are your hobbies, talents and strengths?"

Then, to be instructive, one could suggest, "Please select two or three of these so that together we can work out how they might be incorporated into your health-planning, and help to make you better sooner".

Also, instead of focusing on identification of risks that the client may be exposed to, reframe this to consider safety. So think about "How can our service promote the psychological safety of this client", rather than "What is the risk of self-harm or suicide in this client".

Finally this resilience-based thinking should be applied by nurses and others to research so that the effectiveness of nurse-led interventions can be established, and so that more evidence-based interventions can be developed.

\section{CONCLUSION}

There is much within the context of the health disciplines that needs to be explored, understood and disseminated about resilience and growth through adversity. Resilience research offers the health professions exciting opportunities for preventing health problems with early intervention, enhancing patients' quality of life and wellbeing. Resilience can also benefit the nursing profession itself and can be incorporated into student education, worker development and workplace enrichment. Students typically enter health professions because they sincerely want to care for others. Caring for others skilfully is not just about attending to deficiencies in health, but in cultivating wellbeing. It also involves a high degree of self-giving. Whilst the self can certainly grow and flourish in this experience, it can also suffer. If you aren't prepared for the emotional and cognitive labour involved with caring, then nursing work can become a burden. It can lead to stress, burnout and neglect. Focusing on resilience may be an important solution-focused approach to improving patient outcomes and building a stronger profession.

\section{REFERENCES}

Antonovsky, A. (1987). Unraveling the Mystery of Health: How People Manage Stress and Stay Well. Jossey-Bass, San Francisco.

Baum, F. (2008). The new public health. Melbourne: Oxford University Press.

Boix-Mansilla, V. \& Gardner, H. (1999). On interdisciplinary lenses and interdisciplinary work. In S. Wineburg and P. Grossman (Eds.), Interdisciplinary curriculum: Challenges to implementation (pp. 17-38). New York, NY: Teachers College Press

Boykin, A. W., \& Toms, F. D. (1985). Black child socialization: A conceptual framework. In H. McAdoo, H. Pipes, \& J. L. McAdoo (Eds.), Black children: Social, educational, and parental environments (pp. 33-51). Thousand Oaks, CA: Sage.

Butler, L., Blasey, C., Garlan, R., McCaslin, S., Azarow, J., Chen, X., Spiegel, D. (2005). Posttraumatic growth following the terrorist attacks of September 11, 2001: Cognitive, coping, and trauma symptom predictors in an internet convenience sample. Traumatology , 11 (4), 247-267.

Cassel, L., \& Suedfeld, P (2006). Salutogenesis and autobiographical disclosure among Holocaust survivors. The Journal of Positive Psychology, 1(4), 212 - 225.

Charney, D. (2004). Psychobiological Mechanisms of Resilience and Vulnerability: Implications for Successful Adaptation to Extreme Stress. Focus, 2:368-391.

Chung, O., Li, H., Chiu, S., Lopez, V. (2012). Predisposing Factors to the Quality of Life of Childhood Cancer Survivors. Journal of pediatric oncology nursing, 29, 211220.

Clauss-Ehlers, C., \& Levi, L. (2002). Violence and community, terms in conflict: An ecological approach to resilience. Journal of Social Distress and the Homeless, 11 (4), 265-278.

Deveson, A. (2003). Resilience . Sydney, Australia: Penguin.

Dowling, J., Hockenberry, M., \& Gregory, R. (2003). Sense of Humor, Childhood Cancer Stressors, and Outcomes of Psychosocial Adjustment, Immune Function, and Infection. Journal of pediatric Oncology Nursing, 6, 271292.

Friborg, O., Hjerndal, O., Rosenvinge, J., Martinussen, M. (2003). A new rating scale for adult resilience: What are the central protective resources behind healthy adjustment? International Journal of Methods in Psychiatric Research, 12, 65-76.

Garmezy, N. (1987). Stress, competence, and development: Continuities in the study of schizophrenic adults, children vulnerable to psychopathology, and the search for stress-resistant children. American Journal of 
Orthopsychiatry, 57 (2), 159-174.

Gaynor, L., Gattasch, T., Yorkston, E., Stewart, S., \& Turner, C. (2006). Where do all the undergraduate and new graduate nurses go and why? A search for empirical research evidence. Australian Journal of Advanced Nursing, 24(2), 26-32.

Gillespie, B., Chaboyer, W., Wallis, M., \& Grimbeek, P. (2007). Resilience in the operating room: Developing and testing of a resilience model. Journal of Advanced Nursing, 59 (4), 427-438.

Jackson, D., Firtko, A., \& Edenborough, M. (2007). Personal resilience as a strategy for surviving and thriving in the face of workplace adversity: a literature review. Journal of Advanced Nursing, 60(1), 1-9.

Kauffman, C., Grunebaum, H., Cohler, B., \& Gamer, E. (1979). Superkids: competent children of psychotic mothers. American Journal of Psychiatry, 136(11), 13981402.

Lothe, E., \& Heggen, K. (2003). A study of resilience in young Ethiopian famine survivors. Journal of Transcultural Nursing, 14 (4), 313-320.

Luthar, S. (2003). Resilience and Vulnerability: Adaptation in the Context of Childhood Adversities. Cambridge University Press: New York.

Luthar, S. and Cicchetti, D. (2000). The construct of resilience: implications for interventions and social policies. Development and Psychopathology, 12, pp. 85785.

McAllister, M., \& Lowe, J. (2011). The resilient nurse. New York: Springer.

McAllister, M., Williams, L.,Hope, J., Hallett, C., Framp, A., Doyle, B. McLeod, M. (2011). In my day II: Reflecting on the transformative potential of incorporating celebrations into the nursing curriculum. Nurse Education in Practice, 11(4), 245-249.

McAllister, M., \& McKinnon, J. (2008). The importance of teaching and learning resilience in the health disciplines: A critical review of the literature. Nurse Education Today. http://dx.doi.org/10.1016/j.nedt.2008.10.011

McAllister, M., Tower, M., \& Walker, R. (2007). Gentle interruptions: Transformative approaches to clinical teaching. Journal of Nursing Education, 46(7), 304-13.

Masten, A \& Powell, J. (2003). A Resilience Framework for Research, Policy, and Practice. In Resilience and Vulnerability: Adaptation in the Context of Childhood Adversities (Ed. S. Luthar). New York: Columbia University Press.

Mezirow, J. (2000). Learning as transformation. San Francisco: Jossey Bass.

Noblet, A. (2003). Building health promoting work settings: Identifying the relationship between work characteristics and occupational stress in Australia. Health Promotion International, 18 (4), 351-359.

Poulson, I. (2008). Rise. Sydney: Macmillan.

Rabkin, J., Remien, R., Williams, J., \& Katoff, L. (1993). Resilience in adversity among long-term survivors of AIDS. Hospital and Community Psychiatry, 44 (2), $162-167$.

Robinson, T., \& Sirard, J. (2005). Preventing childhood obesity: A solution-oriented research paradigm. American Journal of Preventive Medicine, 28(2), 194-201.

Rowland, J., \& Baker, F. (2005). Resilience of cancer survivors across the lifespan. Cance, 101 (11 Suppl.), 2543-2548.

Shakespeare-Finch, J., Gow, K., \& Smith, S. (2005). Personality, coping and posttraumatic growth in emergency ambulance personnel. Traumatology, 11 (4), 325-334.

Tusaei, K., \& Dyer, J. (2004). Resilience: A Historical Review of the Construct. Holistic Nursing Practice, 18(1), 3-10.

Wieclaw J., Agerbo E., Mortensen P., et al. (2006). Risk of affective and stress related disorders among employees in human service professions. Occupational Environmental Medicine, 63, 314-319.

Windle, G., Bennett, K., \& Noyes, J. (2011). A methodological review of resilience measurement scales. Health and Quality of life Outcomes, 9:8.

Wiesel, E. (1959). Night. New York: Hill and Wang. 